\title{
Dichotic summation of loudness with small frequency separations
}

\author{
LAWRENCE E. MARKS, DANIEL ALGOM, and JEAN-PIERRE BENOIT \\ The John B. Pierce Laboratory and Yale University, New Haven, Connecticut
}

\begin{abstract}
Subjects gave magnitude estimates of the loudness of monaurally presented pure tones $(1000$, 1040 , and $1080 \mathrm{~Hz}$ ) and dichotically presented pairs of tones $(1000 \mathrm{~Hz}$ to one ear plus 1040 or $1080 \mathrm{~Hz}$ to the other). For each monaural frequency or dichotic pair, the magnitude estimates approximated power functions of sound pressure; moreover, the monaural and dichotic loudness functions were separated by roughly a constant $10 \mathrm{~dB}$, like analogous functions for monaural and diotic stimulation (same frequencies to both ears). These results imply that dichotic addition of loudness is linear in sones.
\end{abstract}

How does the auditory system process the effects of concurrent multiple stimulation? Of the multitude of psychophysically relevant variables, two important ones affecting loudness are the spectral composition of the sounds, including the frequency relations among the various components, and the way in which the sounds are delivered to the ears-for example, either monaurally or binaurally. If the two ears simultaneously hear identical pure tones, the resulting singular sound image appears louder than it would if only one ear heard the tone. This increase in loudness is called binaural summation, and several investigators have reported that the binaural gain-the number of decibels by which a monaural tone has to be augmented to appear as loud as a binaural tone-roughly equals 10 dB (e.g., Algom \& Marks, 1984, 1990; Marks, 1978, 1979, 1980, 1987; but see Causée \& Chavasse, 1942; Scharf, 1969; and Scharf \& Fishken, 1970, for results suggesting smaller binaural gains of only 6-8 dB). Because Stevens's (1956) sone scale of loudness, which grows as the 0.6 power of sound pressure, entails a doubling of loudness with every $10-\mathrm{dB}$ increase in sound pressure, a $10-\mathrm{dB}$ binaural gain consequently means perfect interaural summation of loudness in sones. That is, given the sone scale, and given a binaural gain of $10 \mathrm{~dB}$, a binaural tone's loudness is exactly twice that of a monaural tone of the same SPL.

A second kind of summation takes place when tones of different sound frequencies combine; here, the rule of summation depends on both the difference between the sound frequencies and the way in which the multiple frequency components arrive at the ears. Consider first monaulral stimulation. When two pure tones combine, and the two frequencies fall close together (within a critical band; cf. Scharf, 1970), the overall loudness depends on

Preparation of this paper was supported by NSF Grant BNS76-09950 and NIH Grant DC 00271 . Address correspondence to Lawrence E. Marks, John B. Pierce Laboratory, 290 Congress Avenue, New Haven, CT 06519. the total acoustical energy of the two components; if the components are equally loud, then the two-tone complex will sound only slightly louder than either component alone, and the loudness gain will equal about $3 \mathrm{~dB}$ (Scharf, 1970). Only when the frequency components are widely separated-by many critical bandwidths-do the loudnesses in sones combine additively, such that the loudness gain equals $10 \mathrm{~dB}$.

Consider now diotic stimulation (identical tones to both ears). Again, when two closely spaced tones combine, the loudness is only slightly greater than that of either component alone. For diotic listening, as for monaural listening, the loudness gain introduced by adding an equally loud but subcritically spaced second component is $3 \mathrm{~dB}$ (cf. Algom, Ben-Aharon, \& Cohen-Raz, 1989).

Finally, consider what happens when two sound frequencies are presented neither monaurally (both frequencies to one ear) nor diotically (both to both), but dichotically, with one frequency component going to one ear and the other component to the other ear. In this case, there is only one rule of loudness summation, which is independent of the frequency separation between the components, and it appears to mimic the rule of binaural summation. That is, the dichotic gain for both subcritically and supercritically spaced pairs of sound frequencies equals about 6-10 dB (see, e.g., Algom et al., 1989; Porsolt \& Irwin, 1967; Scharf, 1969).

Taken together, these results are consistent with the notion that critical bands represent some kind of peripheral filter that acts on each monaural input (see, e.g., Scharf, $1969,1970)$. Whether narrowly spaced tones obey a rule of energy summation (total loudness depending on total sound intensity of the components) or loudness summation (total loudness equaling the sum of the loudnesses of the components) depends, therefore, on whether the different frequencies stimulate the same cochlea. When narrowly separated frequency components are presented monaurally (or diotically), they are first processed through the critical-band mechanism, which leads to their mutual interaction and, consequently, to only partial summation 
of loudness; but when the components are presented dichotically, the critical-band mechanism is bypassed, and the additivity of the components is greater.

Although available data are consistent with all of these generalizations (see, e.g., Algom et al., 1989; Porsolt \& Irwin, 1967; Scharf, 1969), different measures of dichotic gain have been reported in different studies. For example, Scharf (1969) reported loudness summation (gain in decibels) to be independent of frequency separation; dichotic gain equaled binaural gain (the gain with only a single sound frequency), but in all cases it was substantially less than $10 \mathrm{~dB}$, thereby indicating less than complete additivity of loudnesses in sones.

Scharf (1969) and Porsolt and Irwin (1967) used directmatching methods to assess summation, whereas Algom et al. (1989) used magnitude estimation, albeit with only a single subcritical frequency separation. Perhaps some or all of the variation in measures of loudness summation represents varying effects of stimulus context, which may differ in matching and in scaling procedures. Recently, we (Algom \& Marks, 1990) showed that measures of loudness summation (gain in decibels) depend critically on stimulus context; context appears not only to affect the ways in which subjects map responses onto perceptual representations, but also to contribute to the quantitative properties of the perceptual representations themselves (see also Schneider \& Parker, 1990). In the present study, magnitude estimation was used to scale loudness and to measure dichotic gain; the stimuli were two pairs of subcritically separated frequency components. We asked: Is dichotic loudness summation additive in sones? That is, do two equally loud frequency components, presented to different ears, produce a dichotic loudness gain of $10 \mathrm{~dB}$ ?

\section{METHOD}

\section{Subjects}

Sixteen young men and women ( 11 men and 5 women) from the Yale community, ranging in age from 18 to 30 , participated. Five of them had had previous experience with the method of magnitude estimation (though not necessarily in judging loudness); the other 11 were unfamiliar with direct scaling of sensory magnitudes.

\footnotetext{
Apparatus and Procedure

The sinusoidal signals from two General Radio oscillators were independently attenuated by General Radio attenuators. These signals were then fed to TDH-39 earphones mounted in MX-41/AR cushions. The signals provided 1-sec rapid onset/offset bursts of 1000-, 1040-, and $1080-\mathrm{Hz}$ tones, presented monaurally to the left or the right ear or dichotically to both.

Seven different levels of sound pressure $(20,25,30,40,50,60$, and $70 \mathrm{~dB}$ SPL) at 1000 and at $1040 \mathrm{~Hz}$ were used during one session of the experiment. The seven levels of pressure at $1000 \mathrm{~Hz}$ and the same seven levels at $1040 \mathrm{~Hz}$ were presented monaurally, a different frequency to each ear. In addition, the subject was presented with $1000+1040 \mathrm{~Hz}$ dichotic complexes at the same SPLs, such that the 1000-Hz component fed one ear and the $1040-\mathrm{Hz}$ component the other. After judging the entire set of 21 tones (7 SPLs in each mode of stimulation: dichotic, left-ear, and right-ear), the subject reversed the headphones (e.g., put the left speaker on the right ear and vice versa) and again judged the whole set of stimuli.

The second session of the experiment comprised the same sequence of modes of presentation, but $1080-\mathrm{Hz}$ tones were substituted for $1040-\mathrm{Hz}$ tones. The order of presentation of stimuli within sessions was irregu-
}

lar and different for each subject, and the sequence of sessions was counterbalanced across subjects.

The method was free-modulus magnitude estimation. The subjects were instructed to assign to the first stimulus whatever number they deemed appropriate to stand for its loudness, then to assign to subsequent stimuli numbers in proportion. Whole numbers, decimals, and fractions were permitted. The number zero would reflect the absence of a sound, but it was reported only twice.

\section{RESULTS AND DISCUSSION}

Figure 1 shows the data pooled over subjects. The magnitude estimates given by the subjects for each stimulus were averaged geometrically, and these means are plotted on a logarithmically spaced ordinate against decibels SPL (which, by definition, are logarithmic units of sound intensity). Note that all of the tones fall well within the width of the critical band (whose value is about $170 \mathrm{~Hz}$ in the range $1000-1080 \mathrm{~Hz}$ ).

Three observations are noteworthy. First, all monaural and dichotic loudness functions, at all but the lowest SPL, approximate power functions (straight lines in the log-log coordinates). In fact, a single function suffices to describe the growth of loudness for both dichotic complexes, though two functions with a small difference in intercept are needed to describe the four monaural functions. Second, all the power functions have exponents of about 0.5 , a bit lower than the 0.6 value that Stevens gave in 1956 to govern the sone scale. Third, and most important, the horizontal separation between the monaural loudness functions at $1000-, 1040-$, and $1080-\mathrm{Hz}$ and the dichotic loudness functions for the $1000+1040$ and $1000+1080 \mathrm{~Hz}$

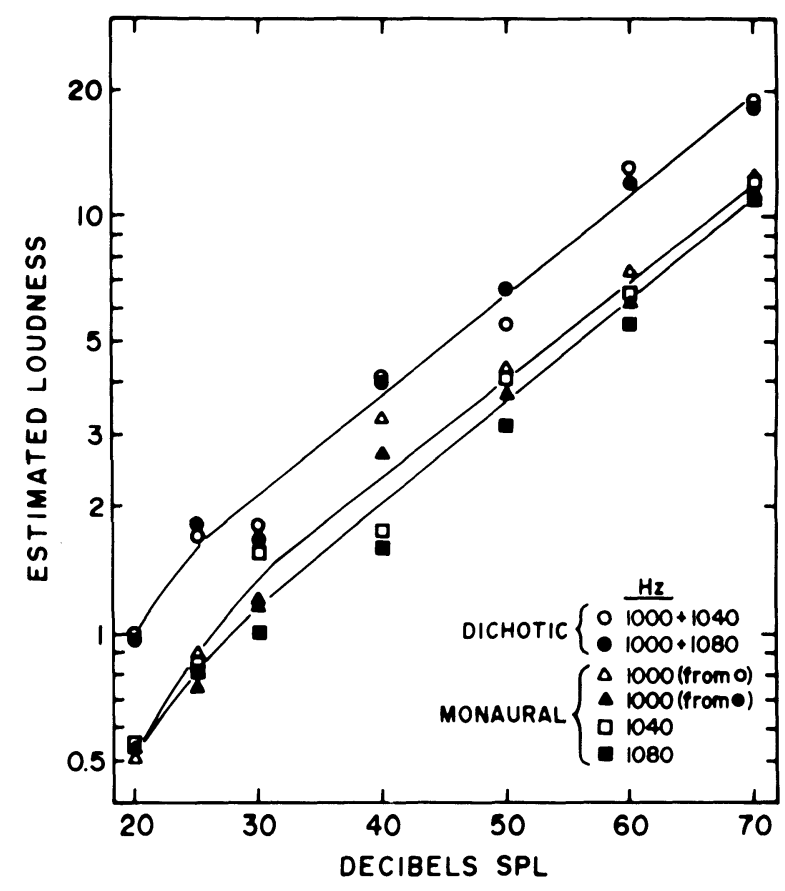

Figure 1. Magnitude estimates of the loudness of 1000-, 1040-, and $1080-\mathrm{Hz}$ tones presented monaurally, and $1000+1040 \mathrm{~Hz}$ and $1000+1080 \mathrm{~Hz}$ pairs presented dichotically (different frequencies but equal SPLs to each ear). 
complexes is constant at about $10 \mathrm{~dB}$. This means that a monaural tone at 1000,1040 , or $1080 \mathrm{~Hz}$ has to be augmented by $10 \mathrm{~dB}$ to sound as loud as a $1000+1040$ or a $1000+1080 \mathrm{~Hz}$ pair heard dichotically (i.e., a different frequency component to each ear).

Recently, Algom et al. (1989) showed that tones as separate as 1000 and $1100 \mathrm{~Hz}$ are processed by the critical-band mechanism, with consequent reduction in loudness summation, if they are presented monaurally or diotically. By contrast, the present results show full additivity of loudness in sones for tones lying even closer in frequency - provided that the components are presented dichotically, that is, a different frequency to each ear. Thus the signals bypass the peripherally based criticalband mechanism and attain the perfect summation usually revealed with same-frequency signals at the two ears (binaural summation).

A final feature of the data deserves mention. Perfect dichotic summation means that the loudness of the dichotic tone pair equals the sum of the input loudnesses of the two components. Since in the present experiment the 1000-, 1040-, and 1080-Hz components were about equally loud (for equal SPL), overall loudness should have been twice that of either component. The obtained average dichotic ratio was about $1.7: 1$. This ratio reflects the fact that although the dichotic gain equaled about $10 \mathrm{~dB}$, the power functions were governed by an exponent of approximately 0.5 . If, however, we rescale the numerical estimates by means of a mild monotonic power transform to bring them to agree fully with sones (this entailed raising the magnitude estimates to the $0.6 / 0.5=1.2$ power), dichotic summation becomes 1.9:1. Thus, there is an intrinsic consistency between measurement of loudness in sones and (almost) complete dichotic summation. A 10-dB separation between the dichotic and single-frequency loudness functions means complete summation in sones, because a $10-\mathrm{dB}$ dichotic gain corresponds to a $2: 1$ ratio of loudness in sones. The monotonic transformation perhaps succeeded in reducing or eliminating nonlinear judgmental biases in the present magnitude estimates.

In conclusion, this study provides a modest addition to the literature on integration processes in hearing. The find- ings further support the notion that dichotic loudness summation obeys an additive rule even with subcritical frequency spacing of components. The amount of summation measured, however, may depend on contextual factors such as the method of judgment.

\section{REFERENCES}

Algom, B., Ben-Aharon, B., \& Cohen-Raz, L. (1989). Dichotic, diotic, and monaural summation of loudness: A comprehensive analysis of composition and psychophysical functions. Perception \& Psychophysics, 46, 567-578.

Algom, D., \& MaRKS, L. E. (1984). Individual differences in loudness processing and loudness scales. Journal of Experimental Psychology: General, 113, 571-593.

Algom, D., \& MARKs, L. E. (1990). Range and regression, loudness scales and loudness processing: Toward a context-bound psychophysics. Journal of Experimental Psychology: Human Perception \& Performance, 16.

Caussée, R., \& Chavasse, P. (1942). Différence entre l'écoute binauriculaire et monauriculaire pour la perception des intensités supraliminaires. Comptes Rendus de la Société de Biologie, 136, 405-406.

MARKs, L. E. (1978). Binaural summation of the loudness of pure tones. Journal of the Acoustical Society of America, 64, 107-113.

MARKS, L. E. (1979). A theory of loudness and loudness judgments. Psychological Review, 86, 256-285.

MARKs, L. E. (1980). Binaural summation of loudness: Noise and twotone complexes. Perception \& Psychophysics, 27, 489-498.

MARKs, L. E. (1987). Binaural versus monaural loudness: Supersummation of tone partially masked by noise. Journal of the Acoustical Society of America, 81, 122-128.

Porsolt, R. D., \& IRWIN, R. J. (1967). Binaural summation in loudness of two tones as a function of their bandwith. American Journal of Psychology, 80, 384-390.

SCHARF, B. (1969). Dichotic summation of loudness. Journal of the Acoustical Society of America, 45, 1193-1205.

SCHARF, B. (1970). Critical bands. In J. Tobias (Ed.), Foundations of modern auditory theory (Vol. 1, pp. 159-202). New York: Academic Press.

SCHARF, B., \& FishKEN, D. (1970). Binaural summation of loudness reconsidered. Journal of Experimental Psychology, 86, 374-379.

SCHNEIDER, B., \& PARKer, S. (1990). Does stimulus context affect loudness or only loudness judgment? Perception \& Psychophysics, 48, 409-418.

STEVENS, S. S. (1956). The direct estimation of sensory magnitudeloudness. American Journal of Psychology, 69, 1-25.

(Manuscript received July 23, 1990.) 